\title{
Exposure to low concentrations of pesticide stimulates ecological functioning in the dung beetle Onthophagus nuchicornis
}

\author{
Paul Manning ${ }^{\text {Corresp., } 1}{ }^{1}$ G. Christopher Cutler ${ }^{1}$ \\ ${ }^{1}$ Department of Plant, Food, and Environmental Sciences, Dalhousie University, Truro, Nova Scotia, Canada \\ Corresponding Author: Paul Manning \\ Email address: paul.manning@dal.ca
}

Body-size is an important trait for predicting how species contribute to ecosystem functions and respond to environmental stress.Using the dung beetle Onthophagus nuchicornis (Coleoptera: Scarabaeidae), we explored how variation in body-size affected ecosystem functioning (dung burial) and sensitivity to an environmental stressor (exposure to the veterinary anthelmintic ivermectin). We found that large beetles buried nearly 1.5 fold more dung than small beetles, but that mortality from exposure to a range of concentrations of ivermectin did not differ between large and small beetles. Unexpectedly, we found that exposure to low concentrations of ivermectin $(0.01-1 \mathrm{mg}$ ivermectin per $\mathrm{kg}$ dung) stimulated dung burial in both small and large beetles. Our results provide evidence of ecological functioning hormesis stemming from exposure to low amounts of a chemical stressor that causes mortality at high doses. 
1 Exposure to low concentrations of pesticide stimulates ecological functioning in the

2 dung beetle Onthophagus nuchicornis

3

4 Paul Manning ${ }^{1}$, G. Chris Cutler ${ }^{1}$

5

6 1. Department of Plant, Food, Environmental Science, Dalhousie University

7

8 Corresponding Author:

9 Paul Manning 1

10 Email address: paul.manning@dal.ca 


\section{Abstract}

13 Body-size is an important trait for predicting how species contribute to ecosystem

14 functions and respond to environmental stress. Using the dung beetle Onthophagus

15 nuchicornis (Coleoptera: Scarabaeidae), we explored how variation in body-size

16 affected ecosystem functioning (dung burial) and sensitivity to an environmental

17 stressor (exposure to the veterinary anthelmintic ivermectin). We found that large

18 beetles buried nearly 1.5 -fold more dung than small beetles, but that mortality from

19 exposure to a range of concentrations of ivermectin did not differ between large and

20 small beetles. Unexpectedly, we found that exposure to low concentrations of

21 ivermectin (0.01 $\square-\square 1 \mathrm{mg}$ ivermectin per kg dung) stimulated dung burial in both small

22 and large beetles. Our results provide evidence of ecological functioning hormesis

23 stemming from exposure to low amounts of a chemical stressor that causes mortality at

24 high doses.

25

26

27

Wolters, 2005)

\section{Introduction}

Insect species vary in their sensitivity and responses to environmental disturbances.

The framework of 'response traits' is useful for understanding mechanisms behind this varied sensitivity (Hevia et al., 2017). Response traits are phenotypic or life history traits that can determine species sensitivity to disturbance. For example, bee species that nest below-ground are more susceptible to soil tillage than species that nest above ground (Williams et al., 2010), and carnivorous carabid beetles are more susceptible to landscape simplification than phytophagous or omnivorous species (Purtauf, Dauber \& 
36 Loss of insect diversity and abundance caused by environmental disturbances affects

37 the functioning of natural and managed ecosystems (Larsen, Williams \& Kremen, 2005;

38 Winfree et al., 2015). A useful framework to predict and understand the implications of

39 declining abundance and diversity on ecosystem functioning is that of 'effect traits';

40 traits that influence a species contribution to an ecosystem function (Lavorel \& Garnier,

41 2002). For example, the ability of a bee to successfully pollinate crops with accessible

42 flowers increases as tongue length decreases (Williams et al., 2010), and the ability of

43 carabid beetles to efficiently kill and consume prey increases with body size (Ball et al., 44 2015).

45

Response traits and effect traits are sometimes interlinked where the traits that make a species susceptible to an environmental disturbance also make that species more or less important in providing an ecosystem function (Nervo et al., 2017). As the field of trait-based research continues to grow, this relationship has become more intensively studied (Hevia et al., 2017). Though most research on the interplay of effect and response traits explores change at the ecosystem or community level, considerable trait variability also occurs within species. Intraspecific trait variation is generated through a combination of genetic and environmental factors and includes body-size, stress tolerance, and personality. Variation in these traits has long been understood to have implications for an individual's fitness, though variation also has significant bearing for ecosystem functioning (Bolnick et al., 2011). 
58 Here, we considered the importance of intraspecific trait variation by exploring the effect 59 of body-size as both an effect trait and response trait in the dung beetle Onthophagus nuchicornis (Coleoptera; Scarabaeoidea). Onthophagus nuchicornis is a generalist

61 coprophage that is native to the Palearctic but has become widely naturalised within 62 North America (Floate \& Kadiri, 2013). In northern North America, it is often highly 63 abundant, representing $80 \%$ or more of the dung beetle community at latitudes above $6444 \mathrm{~N}$ in Western USA (Jones et al., 2019), and c. $40 \%$ of the dung beetles in native grasslands in Alberta (Floate \& Kadiri, 2013). As a tunnelling species, O. nuchicornis buries dung in soil and fashions it into oblong parcels known as 'brood balls'. Females lay a single egg within each brood ball where after hatching, a larva will feed for the entirety of its development (Skidmore, 1991). Burial and subsequent decomposition of the dung by Onthophagus spp. supports ecosystem functions including reductions in abundance of blood-feeding flies (Macqueen \& Beirne, 1975b), improved soil fertility 71 (Macqueen \& Beirne, 1975a), stimulation of plant litter decomposition (Manning et al., 2016), and secondary seed dispersal (Koike et al., 2012).

Within agroecosystems, dung beetles and the ecosystem functions they support are vulnerable to veterinary parasiticides. When parasiticides, including macrocyclic lactones and synthetic pyrethroids, are applied to livestock they are excreted in dung

77 largely unmetabolized (Lumaret et al., 2012). The compound which has perhaps

78 received the most attention is ivermectin. Ivermectin exposure can increase nerve and muscle cell permeability to chloride ions, leading to hyperpolarization that limits action 
81 impaired movement, and death of dung beetles (Verdú et al., 2015; Martínez et al., 82 2017).

83

84 While studies have explored the potential of body-size on sensitivity to environmental 85 disturbances across entire dung beetle communities (e.g. Tonelli, Verdú \& Zunino, 86 2018), to the best of our knowledge none have considered how intraspecific trait 87 variation influences the sensitivity of dung beetles to environmental disturbances. In laboratory experiments using the dung beetle $O$. nuchicornis, we examined the importance of intraspecific body size as a response trait (sensitivity to the veterinary anthelmintic ivermectin) and an effect trait (burial of sheep dung).

We predicted that:

a) Intraspecific variation in body size is a relevant effect trait, such that larger beetles would bury more dung than smaller beetles.

b) Intraspecific variation in body size is not a relevant response trait. Because beetles are exposed to ivermectin through contact and oral exposure as they feed and bury within dung, exposure occurs independently of body size. Larger beetles will be similarly susceptible to ivermectin exposure as smaller beetles.

c) Because low level exposure to ivermectin is known to strongly and negatively

\section{Materials \& Methods}


104 Collection and maintenance of beetles

105 With permission from landowners, we collected O. nuchicornis from two equine facilities 106 in the vicinity of Truro, Nova Scotia (Camden Stables, Opportunity Farm) between $24 \square$ -

10727 June 2019. The horses had not been treated with any sort of parasiticides within the 108 previous four months at either of the two locations. Onthophagus nuchicornis is 109 univoltine and undergoes an obligate reproductive diapause while overwintering as an 110 adult (Floate et al., 2015). Because May and June were especially cold, all beetles we 111 collected were assumed to be overwintered sexually mature adults.

112 Upon return to the laboratory, beetles were housed intermittently in vented $11.4 \mathrm{~L}$

113 polypropylene containers. To each container, we added two dozen crumpled sheets of 114 unbleached paper towel that were wetted with distilled water and $250 \mathrm{~g}$ of horse dung 115 from a facility (Camden Stables) where we collected beetles. An additional $100 \mathrm{~g}$ horse 116 dung was added every three days until beginning the experiment.

118 Dung collection and preparation

119 Fresh sheep dung used in the experiment was collected from a herd of ewes housed 120 indoors at the Dalhousie University Agricultural Campus. Sheep were fed a diet of hay 121 supplemented with a 80:20 barley:high protein pellet. None of the sheep had been 122 treated with any parasiticides within eight months. Fresh sheep dung was collected $12314 \square$-24 June 2019. Each day following collection the dung was homogenized for 10 124 minutes using a paint mixer (Mastercraft, Toronto, Canada) attached to a cordless drill 125 and divided into two equal portions. Dung was frozen at $-21^{\circ} \mathrm{C}$ prior to use in the 126 experiment. Twenty-four hours prior to beginning the experiment, half the dung 
127 collected was removed from the freezer and thawed at room temperature. After the

128 dung was thoroughly homogenized it was weighed and hand-rolled into $100 \mathrm{~g} \mathrm{(+/-} 2 \mathrm{~g})$

129 balls.

130

131 Enclosure design

132 Experimental enclosures (herein containers) were assembled using $1360 \mathrm{~mL}$ grease

133 resistant paper cups (Dart Container Corporation, Mason, Michigan, United States).

134 Eight $2 \mathrm{~mm}$ drainage holes were made in the bottom of each container. Each container

135 was filled with coarse all-purpose builder's sand (Shaw Resources, Shubenacadie,

136 Canada) to a depth of $12 \mathrm{~cm}$ leaving $5.8 \mathrm{~cm}$ between the sand surface and the mouth of

137 the container. Distilled water was slowly added to each container until water began to

138 drip from the drainage holes. Dung was placed on top of the sand and pressed gently

139 against the sand surface to ensure contact.

140

141 Sex and size classification of beetles

142 We collected 358 beetles (170 males, 188 females) from the field. Males were

143 differentiated from females by the presence of a single spine-like horn on the head;

144 females had a transverse ridge at the base of the head and no horn (Jessop, 1986).

145 Cohorts of females and males were placed in separate holding containers partially filled 146 with moist paper towel.

147

148 We labeled $90 \mathrm{~mL}$ plastic specimen cups filled half-way with moist all-purpose builder's

149 sand $(\mathrm{N}=60)$. Cups were labelled from $\mathrm{S} 1-\mathrm{S} 30$ and $\mathrm{L} 1-\mathrm{L} 30$, coding for small and large 
150 beetles, respectively. We then created our sub-population of male beetles by selecting

151 the largest individuals based on sight and placing them individually in cups L1-L30. The

152 order of the cups was randomized, and a second large male beetle was added to each

153 cup. We repeated the same process for large female beetles, such that each cup

154 contained four beetles (two males and two females) sampled from the larger end of the

155 size distribution. Immediately after the last beetle was added, the container was closed

156 with 2-mm black fibreglass mesh secured by an elastic band. Immediately after, the

157 same process was followed for small beetles placing them in cups labeled from S1-

158 S30. All remaining beetles were released.

159

160 Estimating the importance of body size in functioning

161 We added beetles from cups into containers on 28 June. Beetles were left to bury and

162 feed on dung for seven days. On 5 July we gently sifted the contents of each container

163 through a $0.4 \mathrm{~cm}$ aperture soil sieve. After sifting, all beetles were gently removed and

164 placed in a $90 \mathrm{~mL}$ specimen cup, and all brood balls were placed in a Petri dish. We

165 recorded the number of brood balls formed in each container and measured the

166 cumulative mass of buried dung to the nearest tenth of a gram. We measured the mass

167 of each beetle to the nearest milligram. Three beetles died in the first part of the

168 experiment and were replaced with beetles of the same size and sex housed under

169 identical conditions.

170

171 Estimating intraspecific variation in functioning under chemical perturbation

172 The same beetles were used for the second experiment, which began immediately after 
173 the first experiment. Dung was defrosted 48 hours prior and was subsequently

174 homogenized for 10 minutes as described above. We subdivided the dung into six 1.0

$175 \mathrm{~kg}$ portions. We added $100 \mathrm{~mL}$ of Ivomec, Pour-On for Cattle $\left(5 \mathrm{mg} \cdot \mathrm{mL}^{-1}\right.$ ivermectin)

176 diluted in acetone to each portion of dung. The final treatment concentrations of

177 ivermectin in dung were $0.01,0.1,1,10$, and $100 \mathrm{mg} \cdot \mathrm{kg}^{-1}$ (wet weight). A $100 \mathrm{~mL}$

178 solution of pure acetone was added to the remaining $1.00 \mathrm{~kg}$ portion of dung to serve as

179 a control treatment. As before, we homogenized the dung using an electric paint mixer

180 and divided each parcel into $\mathrm{n}=10$ dung balls each measuring $100 \mathrm{~g}$. To avoid

181 contamination, when mixing ivermectin into the dung we moved sequentially from the

182 ivermectin-free controls to the highest concentration of ivermectin. The paint mixer

183 attachment was thoroughly cleaned in hot soapy water, rinsed, and dried between

184 mixing different batches of dung. We left all the dung in a well-ventilated area for $24 \mathrm{~h}$ to 185 allow the acetone to volatize.

187 We began the second experiment as the first experiment (described in section 2.5) was

ending ( 5 July). As beetles and their brood were removed from each container, we

repacked the sand into each enclosure and re-wetted as before. The dung balls

190 containing ivermectin were split amongst size classes (e.g. $n=5$ "large beetle" containers

with $10 \mathrm{mg} \cdot \mathrm{kg}^{-1}$ ivermectin and $\mathrm{n}=5$ "small beetle" containers with $10 \mathrm{mg} \cdot \mathrm{kg}^{-1}$ ivermectin)

192 that were pre-assigned using a random number generator. Levels of ivermectin

exposure were then randomly assigned to containers. We added a dung ball to each

194 container, pressing the dung gently against the soil surface to ensure contact between

195 the sand and dung. Beetles were added to containers immediately after being weighed 
196 and each container was closed with $2 \mathrm{~mm}$ black fibreglass mesh and secured with two

197 rubber bands to ensure the beetles could not escape.

198

199 Following a seven-day period (12 July) the experiment was completed. We were blinded 200 from the concentration of the ivermectin during observation. As before, we used a sieve

201 to separate beetles and brood balls from sand. We recorded the number and cumulative 202 mass of brood balls within each enclosure. We recorded the sex of each beetle, and 203 whether it was dead or alive. A beetle was considered dead if gentle prodding with a 204 pair of blunt forceps, or if breathing onto the beetle failed to elicit any significant 205 antennal or leg movements. Beetles were subsequently euthanized by freezing at $20621^{\circ} \mathrm{C}$, and later a second estimate of body size (pronotal width) was taken using digital 207 calipers to the nearest hundredth of a millimeter. While measuring pronotal width, we 208 detected an error in differentiating male and female beetles that occurred in three 209 mesocosms. The final sample size was reduced from $N=60$ to $N=57$.

210

\section{Statistical Analysis}

212 To confirm that body size differed between the small and large groups, we used a two213 sample t-test that compared pronotal width and mass between the two size 214 classifications. Because O. nuchicornis is sexually dimorphic, we completed separate 215 tests for males and for females.

217 To determine whether intraspecific variation in body size is a relevant effect trait, we 218 compared small and large beetles across three measures of functioning. We used a 
219 two-sample t-test to compare mean dung ball mass and cumulative mass of dung 220 buried. We used a linear model with a Poisson error structure to determine if the 221 number of brood balls varied between small and large beetles.

222

223 To determine if intraspecific variation in body size is a relevant response trait, we initially 224 intended to compare by probit analysis the sensitivity of beetles between the size 225 classes by calculating the ivermectin concentration that kills $50 \%$ of the population. This 226 was not possible because of relatively high $(15 \pm 5 \%)$ mortality in the control group and 227 failure to select an experimental dose high enough to generate the full sigmoidal dose228 response curve. We instead treated dose as a categorical factor and compared mortality across the full range of doses using generalized linear models with a binomial 230 error structure. Where overdispersion occurred, models were compared using generalized linear model with quasi-binomial error structure. Statistical significance was 232 calculated by through comparison to a null, intercept-only, model using an "F" test for 233 models with binomial error, and a "Chi-Square" test for models with quasibinomial error.

Lastly, to test whether ecosystem functioning provided by beetles with a larger body size would be less impaired by ivermectin in comparison to beetles with a smaller body 237 size, we used generalized linear models. Ivermectin concentration (categorical: 0.01$238100 \mathrm{mg} \cdot \mathrm{kg}^{-1}$ ) and body size (categorical: small vs. large) were used as independent 239 variables along with their interaction. As above, we used three different estimates of 240 functioning as dependent variables: dung removal (Gaussian error structure), mean 
241 brood ball size (Gaussian error structure), and brood ball number (Poisson error 242 structure).

243

244 All statistical models were run using R 3.6.2 (R Core Team, 2016), along with the 245 packages, dplyr (Wickham et al., 2015)) and ggplot2 (Wickham, 2016). When reporting 246 results, in all cases we have used means and associated standard errors.

247

248

249

250

251

252

253

254

255

256

257

258

259

260

261

262

263

264

\section{Results}

Beetles varied significantly in size between population samples

Our efforts to select a sample of large and small beetles from the larger population were effective. The mean mass of large males $(61.8 \pm 1.0 \mathrm{mg})$ was $46 \%$ heavier than the mass of small males $\left(42.2 \pm 0.8 \mathrm{mg}, \mathrm{t}_{112}=16.4, P<0.001\right.$, Fig. $\left.1 \mathrm{~A}\right)$. The pronotal width of large males $(4.51 \mathrm{~mm} \pm 0.02 \mathrm{~mm})$ was $15 \%$ greater than the pronotal width of small males $\left(3.93 \pm 0.02 \mathrm{~mm}, \mathrm{t}_{112}=18.8, P<0.001\right.$, Fig. $\left.1 \mathrm{~B}\right)$. Mean mass of large females (64.6 $\pm 1.1 \mathrm{mg})$ was $84 \%$ greater than the mass of small females $\left(34.3 \pm 0.8 \mathrm{mg}, \mathrm{t}_{112}=21.5\right.$, $P<0.001$, Fig. 1 C). The pronotal width of large females $(4.53 \pm 0.02 \mathrm{~mm})$ was nearly $25 \%$ greater than the pronotal width of small females $\left(3.61 \pm 0.03 \mathrm{~mm}, \mathrm{t}_{112}=22.8\right.$, $P<0.001$, Fig. 1D).

\section{Intraspecific body size is a highly relevant effect trait}

Larger beetles buried 1.5-fold more dung $(47.6 \pm 2.8 \mathrm{~g})$ than smaller beetles $(19.0 \pm 2.3$ $\mathrm{g}, \mathrm{t}_{54}=7.84, \mathrm{P}<0.001$, Fig $2 \mathrm{~A}$ ). Larger beetles buried nearly twice as many brood balls $(17.1 \pm 0.88 \mathrm{~g})$ in comparison to smaller beetles $\left(9.62 \pm 1.10, F_{1,55}=20.33, P<0.001\right.$, Fig. $2 B)$. 
265 The mean mass of brood balls formed by large beetles $(2.78 \pm 0.09 \mathrm{~g})$ was $38 \%$

266 heavier than the mean mass of brood balls formed by smaller beetles $(2.01 \pm 0.10 \mathrm{~g}$,

$267 t_{51}=5.80, P<0.001$, Fig $\left.2 C\right)$.

268

269

Beetles susceptibility to ivermectin does not vary with body size

270 We found no significant interaction between body-size and exposure level on beetle

271 mortality $\left(X_{5,45}=3.80, P=0.57\right)$. While beetle sensitivity to ivermectin was not significantly

272 affected by body size $\left(X_{1,54}=0.507, P=0.48\right)$, the level of ivermectin exposure

273 significantly affected survival $\left(X_{5,50}=54.5, P<0.001\right.$, Fig. 3$)$. Beetle survival in the control

274 group was $85 \pm 6 \%$, increasing to $97 \pm 3 \%, 93 \pm 4 \%$, and $97 \pm 3 \%$ at $0.01,0.1$, and 1

$275 \mathrm{mg}$ ivermectin $\cdot \mathrm{kg}^{-1}$ dung respectively. Survival dropped to $68 \pm 13 \%$ at $10 \mathrm{mg}$

276 ivermectin $\cdot \mathrm{kg}^{-1}$ dung and $8 \pm 4 \%$ at $100 \mathrm{mg}$ ivermectin $\cdot \mathrm{kg}^{-1}$ dung.

277

278 Exposure to low concentrations of ivermectin stimulates functioning

279 Total dung buried was significantly affected by beetle size $\left(F_{1,54}=4.16, P=0.04\right)$ and by

280 ivermectin exposure $\left(F_{5,49}=3.00, P=0.004\right)$, but not by the interaction of these factors

$281\left(F_{5,44}=1.00, P=0.43\right)(F i g .4 A)$. Low level exposure to ivermectin stimulated functional

282 efficiency. Relative to dung buried by beetles not exposed to ivermectin $(1.16 \pm 0.57 \mathrm{~g}$

$283 \mathrm{~g}$ ), beetles exposed to $0.01 \mathrm{mg} \cdot \mathrm{kg}^{-1}$ ivermectin buried 13.7 -fold more dung (15.9 $\left.\pm 8.4 \mathrm{~g}\right)$,

284 beetles exposed to $0.1 \mathrm{mg} \cdot \mathrm{kg}^{-1}$ ivermectin buried 10.8 -fold more dung (12.6 $\left.\pm 3.6 \mathrm{~g}\right)$,

285 and beetles exposed to $1 \mathrm{mg} \cdot \mathrm{kg}^{-1}$ ivermectin buried 6 -fold more dung $(6.9 \pm 1.9 \mathrm{~g})$. At

286 higher concentrations dung burial was negatively affected where exposure to $10 \mathrm{mg} \cdot \mathrm{kg}^{-1}$

287 ivermectin reduced dung burial to by $54 \%(0.53 \pm 0.36 \mathrm{~g})$ and exposure to $100 \mathrm{mg} \cdot \mathrm{kg}^{-1}$ 
288 ivermectin reduced dung burial by $81 \%(0.22 \pm 0.22 \mathrm{~g})$. Across all levels of ivermectin 289 exposure, larger beetles buried $8.6 \pm 3.0 \mathrm{~g}$ of dung, which was approximately 1.75 -fold 290 more dung than smaller beetles $(3.1 \pm 0.9 \mathrm{~g})$.

291

292 We found a similar trend for brood ball production (Fig. 4B). The number of brood balls 293 buried per mesocosm was significantly affected by beetle size $\left(F_{1,55}=14.36, P=0.01\right)$ and 294 by ivermectin exposure $\left(F_{5,50}=121.9, P<0.001\right)$, but not by their interaction $\left(F_{5,45}=4.31\right.$, 295 $\mathrm{P}=0.82$ ). Low level exposure to ivermectin stimulated production of brood balls. Relative 296 to the number of brood balls produced by beetles that were not exposed to ivermectin 297 ( $0.60 \pm 0.26$ brood balls), beetles exposed to $0.01 \mathrm{mg} \cdot \mathrm{kg}^{-1}$ ivermectin buried 10 -fold ( 5.4 $298 \pm 2.4$ brood balls) more brood balls, and beetles exposed to $0.1 \mathrm{mg} \cdot \mathrm{kg}^{-1}$ ivermectin 299 buried more 8 -fold more ( $4.8 \pm 1.2$ brood balls, Fig. 1A). Across all levels of ivermectin 300 exposure, larger beetles buried twice as many brood balls $(3.0 \pm 0.9)$ as smaller beetles 301 (1.4 \pm 0.4 brood balls).

302

303 The mean size of brood balls (Fig. 4 C) was not affected by beetle size $\left(F_{1,27}=2.82\right.$, $304 P=0.11$, ), ivermectin exposure $\left(F_{5,22}=0.33, P=0.89\right)$, or the interaction of these factors $305\left(\mathrm{~F}_{3,19}=0.50, P=0.69\right)$.

306

\section{Discussion}

308 Beetles with a larger body-size were more efficient at removing dung suggesting that 309 body-size is an important intraspecific effect trait for O. nuchicornis. This trend has been 310 observed for other species of dung beetles including Onthophagus (Lee \& Peng, 1981). 
311 The greater level of functional efficiency in large beetles can explained by two

312 complementary factors. Larger beetles produced nearly twice as many brood balls as

313 smaller beetles, and the mean size of brood balls by large beetles was $38 \%$ greater

314 than brood balls produced by smaller beetles. These observed differences can be

315 explained through biological and behavioural mechanisms.

316

317 The greater number of brood balls constructed by larger beetles may be directly related

318 to fecundity. Female body-size is positively and strongly linked to fecundity across many

319 insect groups (Honěk, 1993). However, in O. nuchicornis, both males and females

320 contribute to formation of brood balls (Macqueen \& Beirne, 1975a), meaning the

321 number of brood balls constructed by a pair of beetles reflects more than fecundity

322 alone.

323

324 The larger size of brood balls can be explained by both behavioural and morphological

325 differences amongst size classes. A behavioral explanation of these differences is

326 linked to reproductive investment by females. A study of a closely-related species, $O$.

327 taurus, found that female beetles formed larger brood balls, when mated to larger

328 bodied males (Hunt \& Simmons, 2001). Because we modified male and female size

329 simultaneously, we are unable to test whether this effect occurred within our study

330 species. Onthophagine dung beetles use their legs and bodies to combine small

331 quantities of dung into tightly-packed masses known as brood balls. Because of their

332 greater size, larger beetles should build larger brood balls in comparison to smaller 
333 beetles. Past research focusing on $O$. gazella found similar positive relationships

334 between body size and brood ball size (Lee \& Peng, 1981).

335

336 Although mortality of O. nuchicornis to ivermectin was significant at concentrations of 10 $337 \mathrm{mg} \cdot \mathrm{kg}^{-1}\left(\sim 35 \%\right.$ mortality) and $100 \mathrm{mg} \cdot \mathrm{kg}^{-1}(\sim 90 \%$ mortality), larger body size continued 338 to support higher levels of functional efficiency. That is, irrespective of ivermectin 339 exposure, large beetles buried more dung than smaller beetles. Unlike in the first part of

340 the experiment, this was caused solely by brood ball abundance and not by a 341 combination of brood ball abundance and size. Comparing brood ball production from

342 the first experiment with the control group in the second experiment, shows

343 considerable loss of functional efficiency over time. This could indicate that laboratory

344 conditions were not conducive to beetle health, or that field captured beetles were

345 collected when their reproductive potential was declining.

347 Dung beetles exposed to low levels of ivermectin had greater functional efficiency and 348 higher survival rates than beetles in the control treatment. This response is indicative of 349 hormesis: a biphasic dose-response relationship where low doses of a stressor 350 stimulate biological effects and high doses of the same stressor inhibit biological effects 351 (Southam, 1943). While the phenomenon of hormesis has been observed across many 352 different insect taxa (Cohen, 2006; Cutler, 2013; Guedes \& Cutler, 2014), to the best of 353 our knowledge this is the first time it has been recognized as such in dung beetles.

354 However, previous studies seem to have observed stimulatory effects of ivermectin on 355 other dung beetle species, but the authors have not acknowledged the hormetic effects 
356 they reported. In a pair of studies by Ishikawa \& Iwasa, (2020), exposure to $0.1 \mathrm{ppm}$ 357 ivermectin in cow dung increased brood ball production $32 \%$ in Onthophagus bivertex, 358 and $52 \%$ in Onthophagus lenzii. A similar finding was reported by Iwasa et al., (2007) 359 who reported that exposure to $0.05-0.5 \mathrm{ppm}$ (wet weight) ivermectin in cow dung 360 increased brood ball formation by as much as $198 \%$ in the dung beetle Caccobius 361 jessoensis, relative to an ivermectin-free control. 362

363 The range of ivermectin concentrations that stimulated a hormetic response in our 364 experiment $\left(0.01-1 \mathrm{mg} \mathrm{kg}^{-1}\right)$, are commonly encountered in agroecosystems. A 365 pharmokinetic study of ivermectin in sheep (Vokřál et al., 2019), where animals were 366 dosed with a subcutaneous injection of 0.2 mg ivermectin $\mathrm{kg}^{-1}$ bodyweight resulted in a 367 maximum concentration of $0.93 \pm 0.50 \mathrm{mg} \mathrm{kg}^{-1}$ ivermectin in dung (wet weight) $48 \mathrm{~h}$ 368 following injection, which quickly declined to approximately $0.05 \mathrm{mg} \mathrm{kg}^{-1} 12$ days post 369 treatment. Experiments with cattle also demonstrate the hormetic concentrations in our experiments also occur in the field. For example, after treating cattle with a pour-on

371 application of $500 \mu \mathrm{g}$ ivermectin $\mathrm{kg}_{\text {bodyweight }}{ }^{-1}$, concentrations of ivermectin in dung 372 were $0.97-1.01,0.50-1.54$, and $0.07-0.14 \mathrm{mg} \mathrm{kg}^{-1}$ wet weight at 3,7 and 14 days 373 respectively (Wohde et al., 2016). Concentrations of ivermectin in dung can be above 374 these sublethal concentrations depending on the product formulation (Sommer et al., 375 1992), species receiving the treatment (Canga et al., 2009), and occurrence of social 376 grooming behaviours (Laffont et al. 2001). 
379 We found that ecosystem functioning by a common and highly abundant species can be 380 stimulated by exposure to low concentrations of ivermectin in dung. This has potentially 381 far-reaching beneficial effects for pasture environments. By increasing the quantity of 382 dung buried in soil, tunnelling dung beetles like 0 . nuchicornis move greater quantities 383 of nutrients into the plant root zone, which stimulates primary productivity. Increased 384 burial also results in clearing of dung from the pasture surface, which frees additional 385 pasture area for grazing livestock (Anderson, Merritt \& Loomis, 1984). Dung burial by 386 tunneling beetles is well known to prevent the development of blood-feeding veterinary 387 pests such as Haematobia irritans (Diptera: Muscidae) (Legner \& Warkentin, 1991). 388 Furthermore, enhanced dung burial and physical disruption of the dung environment 389 could work alongside the toxic effects of ivermectin on horn fly development, and might 390 complement programs developed to manage resistance to ivermectin and other

391 macrocyclic lactones (Byford et al., 1999).

392

While low-dose exposure to ivermectin stimulated higher levels of functioning than the 394 controls, it is important to reiterate the loss of functional efficiency between the first and second experiment. Beetles that experienced no ivermectin-exposure in the second experiment buried on average just $2.2 \pm 0.27$ brood balls, whereas the same cohort of 397 the beetles in the first experiment buried $10.6 \pm 2.57$ brood balls, representing a $\sim 80 \%$ reduction between the two experiments. It seems likely that the experimental conditions were not conducive to prolonged insect health. The hormetic response of dung beetles to ivermectin during the second part of the experiment might not have been as 401 pronounced in a less stressful environment. 
402

403 Trade-offs may have occurred with biological endpoints not measured in our study. For

404 example, others have shown that exposure of dung beetles to ivermectin in dung

405 stimulates broodball formation, but thereafter results in reduced emergence of F1

406 offspring (Ishikawa \& Iwasa, 2020). This may be because of greater ivermectin

407 sensitivity in developing larvae relative to adult beetles, which has been reported in

408 multiple studies (Beynon et al., 2012; Pérez-Cogollo et al., 2015). More work is needed

409 to clarify whether ecological benefits of enhanced dung processing stemming from

410 exposure to low doses of ivermectin results in increased functioning of the system

411 overall, or neutralized or reduced functioning as a result of trade-offs.

412

413 Our findings must be considered against landscape-scale studies that indicate negative

414 impacts of veterinary parasiticides on dung beetles. Sands and Wall (2018) sampled

415 dung beetles across 24 beef farms across Southwest England, finding farms that used

416 macrocyclic lactones had 19\% fewer species of dung beetles, but no reduced

417 abundance, compared to farms that used no parasiticides. While not specifically

418 targeting the effect of veterinary parasiticides, a study of 24 cattle farms in Ireland by

419 Hutton and Giller (2003) found that organic farms supported dung beetle abundance

$42050 \%$ greater than conventional farms. Short-term benefits for ecosystem functioning

421 caused by hormesis may be short-lived if dung beetle populations experience decline in

422 abundance and diversity: both of which have been shown to negatively affect

423 ecosystem functions provided by dung beetles (e.g. Beynon et al. 2012; Manning and

424 Cutler 2018). 
426 Relatively little is known about how short-term exposure to parasiticide residues

427 impacts beetles later in life. When Aphodius fossor fed on dung containing $0.5 \mathrm{mg} \mathrm{kg}^{-1}$

428 ivermectin, dung removal was suppressed $48 \%$ relative to beetles feeding on

429 ivermectin-free dung, but such effects subsided two weeks after exposure (Manning,

430 Beynon \& Lewis, 2017). If low-dose exposure to ivermectin can stimulate reproduction,

431 hormetic effects could have a net positive effect on ecosystem functioning. Past

432 research indicates this is possible: males of the dung beetle Euoniticellus intermedius

433 exposed to $0.01 \mathrm{mg} \mathrm{kg}^{-1}$ ivermectin in cattle dung had $39 \%$ increased testis volumes,

434 which is indicative of higher fertility (Hunt \& Simmons, 2001), and females exposed to

435 the same ivermectin treatment had 25\% more mature oocytes (a measure of fecundity),

436 with no effect on the number of brood masses formed; a second measure of fecundity.

438 Our current understanding of insecticide-induced hormesis is mostly limited to

439 laboratory conditions, despite the ramifications this phenomenon could have for

440 ecosystems (Cutler, 2013). Dung insect communities perturbed by parasiticide residues

441 could be an excellent model system to better understand the strength and significance

442 of hormetic relationships in complex environments subject to ecological flux and

443 chemical disturbance. In conjunction with feeding on the dung of livestock, dung beetles

444 support a wide range of ecosystem functions within agroecosystems that vary from

445 enhancing primary productivity (Manning et al., 2017) to disrupting parasite

446 development (Sands \& Wall, 2017). This offers a range of endpoints and experimental 
447 designs that can be used to better understand hormetic influences of stressors on 448 ecosystem functioning.

449 
450 Conclusions

451 We found that body size was a strong predictor of functional efficiency for the dung

452 beetle Onthophagus nuchicornis. This benefit of larger body size for functional efficiency

453 persisted, even when beetles were exposed to the veterinary anthelmintic ivermectin.

454 High concentrations of ivermectin in dung $\left(10-100 \mathrm{mg} \cdot \mathrm{kg}^{-1}\right)$ caused mortality; but low

455 concentrations $\left(0.01-1 \mathrm{mg} \cdot \mathrm{kg}^{-1}\right)$ stimulated the amount of dung buried via increasing the

456 number of brood ball production. This hormetic response of Onthphagus dung beetles

457 to ivermectin has been reported in earlier publications but was not recognized as

458 hormesis. Because dung beetles support healthy agroecosystems by providing a

459 number of ecological functions, we suggest that dung beetles could be a useful system

460 for understanding the significance of hormesis within ecosystems.

461

462

463

464

465

466

467

468

469

470

471

472

473

474

475

476

477

478

479

480

481

482

\section{Acknowledgements}

We wish to thank Alexa Stack-Mills for assistance in the field and Emma Gray and Janessa Rathgeber for assistance in the lab.

\section{References}

Anderson JR, Merritt RW, Loomis EC. 1984. The insect-free cattle dropping and its relationship to increased dung fouling of rangeland pastures. Journal of Economic Entomology 77:133-141.

Ball SL, Woodcock BA, Potts SG, Heard MS. 2015. Size matters: Body size determines functional responses of ground beetle interactions. Basic and Applied Ecology 16:621-628. DOI: 10.1016/j.baae.2015.06.001.

Beynon SA, Mann DJ, Slade EM, Lewis OT. 2012. Species-rich dung beetle communities buffer ecosystem services in perturbed agro-ecosystems. Journal of Applied Ecology 49:1365-1372. DOI: 10.1111/j.1365-2664.2012.02210.x.

Bolnick DI, Amarasekare P, Araújo MS, Bürger R, Levine JM, Novak M, Rudolf VHW, Schreiber SJ, Urban MC, Vasseur DA. 2011. Why intraspecific trait variation matters in community ecology. Trends in Ecology \& Evolution 26:183-192. DOI: 
483

484

485

486

487

488

489

490

491

492

493

494

495

496

497

498

499

500

501

502

503

504

505

506

507

508

509

510

511

512

513

514

515

516

517

518

519

520

521

522

10.1016/j.tree.2011.01.009.

Byford RL, Craig ME, DeRouen SM, Kimball MD, Morrison DG, Wyatt WE, Foil LD. 1999. Influence of permethrin, diazinon and ivermectin treatments on insecticide resistance in the horn fly (Diptera: Muscidae). International Journal for Parasitology 29:125-135. DOI: 10.1016/S0020-7519(98)00196-9.

Canga AG, Prieto AMS, Liébana MJD, Martínez NF, Vega MS, Vieitez JJG. 2009. The pharmacokinetics and metabolism of ivermectin in domestic animal species. The Veterinary Journal 179:25-37.

Cohen E. 2006. Pesticide-mediated homeostatic modulation in arthropods. Pesticide Biochemistry and Physiology 85:21-27.

Cutler GC. 2013. Insects, insecticides and hormesis: evidence and considerations for study. Dose-Response 11:154-177.

Floate KD, Kadiri N. 2013. Dung beetles (Coleoptera: Scarabaeidae) associated with cattle dung on native grasslands of southern Alberta, Canada. The Canadian Entomologist 145:647-654. DOI: 10.4039/tce.2013.50.

Floate KD, Watson DW, Coghlin P, Olfert O. 2015. Degree-day models for development of the dung beetles Onthophagus nuchicornis, O. taurus, and Digitonthophagus gazella (Coleoptera: Scarabaeidae), and the likelihood of $O$. taurus establishment in southern Alberta, Canada. The Canadian Entomologist 147:617-627. DOI: $10.4039 /$ tce.2014.70.

Guedes RNC, Cutler GC. 2014. Insecticide-induced hormesis and arthropod pest management. Pest Management Science 70:690-697.

Hevia V, Martín-López B, Palomo S, García-Llorente M, Bello F de, González JA. 2017. Trait-based approaches to analyze links between the drivers of change and ecosystem services: Synthesizing existing evidence and future challenges. Ecology and Evolution 7:831-844. DOI: 10.1002/ece3.2692.

Honěk A. 1993. Intraspecific variation in body Size and fecundity in insects: A General Relationship. Oikos 66:483-492. DOI: 10.2307/3544943.

Hunt J, Simmons LW. 2001. Status-dependent selection in the dimorphic beetle Onthophagus taurus. Proceedings. Biological sciences 268:2409-14. DOI: 
523

524

525

526

527

528

529

530

531

532

533

534

535

536

537

538

539

540

541

542

543

544

545

546

547

548

549

550

551

552

553

554

555

556

557

558

559

560

561

10.1098/rspb.2001.1758.

Hutton SA, Giller PS. 2003. The effects of the intensification of agriculture on northern temperate dung beetle communities. Journal of Applied Ecology 40:994-1007. DOI: 10.1111/j.1365-2664.2003.00863.x.

Ishikawa I, Iwasa M. 2020. Toxicological effect of ivermectin on the survival, reproduction, and feeding activity of four species of dung beetles (Coleoptera: Scarabaeidae and Geotrupidae) in Japan. Bulletin of Entomological Research 110:106114. DOI: $10.1017 /$ S0007485319000385.

Iwasa M, Maruo T, Ueda M, Yamashita N. 2007. Adverse effects of ivermectin on the dung beetles, Caccobius jessoensis Harold, and rare species, Copris ochus Motschulsky and Copris acutidens Motschulsky (Coleoptera: Scarabaeidae), in Japan. Bulletin of Entomological Research 97:619-625. DOI: 10.1017/S0007485307005329.

Jones MS, Fu Z, Reganold JP, Karp DS, Besser TE, Tylianakis JM, Snyder WE. 2019. Organic farming promotes biotic resistance to foodborne human pathogens. Journal of Applied Ecology 56:1117-1127. DOI: 10.1111/1365-2664.13365.

Koike S, Morimoto H, Kozakai C, Arimoto I, Soga M, Yamazaki K, Koganezawa M. 2012. The role of dung beetles as a secondary seed disperser after dispersal by frugivore mammals in a temperate deciduous forest. Acta Oecologica 41:74-81. DOI: 10.1016/j.actao.2012.04.009.

Laffont CM, Alvinerie M, Bousquet-Mélou A, Toutain P-L. 2001. Licking behaviour and environmental contamination arising from pour-on ivermectin for cattle. International Journal for Parasitology 31:1687-1692.

Larsen TH, Williams NM, Kremen C. 2005. Extinction order and altered community structure rapidly disrupt ecosystem functioning. Ecology Letters 8:538-547. DOI: 10.1111/j.1461-0248.2005.00749.x.

Lavorel S, Garnier E. 2002. Predicting changes in community composition and ecosystem functioning from plant traits: revisiting the Holy Grail. Functional Ecology 16:545-556. DOI: 10.1046/j.1365-2435.2002.00664.x.

Lee JM, Peng Y-S. 1981. Influence of adult size of Onthophagus gazella on manure pat degradation, nest construction, and progeny size. Environmental Entomology 10:626- 
562630.

563

564

565

Legner EF, Warkentin RW. 1991. Influence of Onthophagus gazella on hornfly,

566 Haematobia irritans density in irrigated pastures. Entomophaga 36:547-553. DOI:

567

568

569 10.1007/BF02374437.

\section{0}

571

572

573

574

575

576

577

578

579

580

581

582

583

584

585

586

587

588

589

590

591

592

593

594

595

596

597

Lumaret J-P, Errouissi F, Floate K, Rombke J, Wardhaugh K. 2012. A review on the toxicity and non-target effects of macrocyclic lactones in terrestrial and aquatic environments. Current Pharmaceutical Biotechnology 13:1004-1060. DOI: $10.2174 / 138920112800399257$.

Macqueen A, Beirne BP. 1975a. Effects of cattle dung and dung beetle activity on growth of beardless wheatgrass in British Columbia. Canadian Journal of Plant Science 55:961-967. DOI: 10.4141/cjps75-152.

Macqueen A, Beirne BP. 1975b. Dung burial activity and fly control potential of Onthophagus nuchicornis (Coleoptera: Scarabaeinae) in British Columbia. The Canadian Entomologist 107:1215-1220. DOI: 10.4039/Ent1071215-11.

Manning P, Beynon SA, Lewis OT. 2017. Quantifying immediate and delayed effects of anthelmintic exposure on ecosystem functioning supported by a common dung beetle species. PLOS ONE 12:e0182730. DOI: 10.1371/journal.pone.0182730.

Manning P, Cutler GC. 2018. Ecosystem functioning is more strongly impaired by reducing dung beetle abundance than by reducing species richness. Agriculture, Ecosystems \& Environment 264:9-14. DOI: 10.1016/J.AGEE.2018.05.002

Manning P, Slade EM, Beynon SA, Lewis OT. 2016. Functionally rich dung beetle assemblages are required to provide multiple ecosystem services. Agriculture, Ecosystems and Environment 218:87-94. DOI: 10.1016/j.agee.2015.11.007.

Manning P, Slade EM, Beynon SA, Lewis OT. 2017. Effect of dung beetle species richness and chemical perturbation on multiple ecosystem functions. Ecological Entomology 41:577-586. DOI: 10.1111/een.12421.

Martínez I, Lumaret J-P, Ortiz Zayas R, Kadiri N. 2017. The effects of sublethal and 598 lethal doses of ivermectin on the reproductive physiology and larval development of the

599 dung beetle Euoniticellus intermedius (Coleoptera: Scarabaeidae). The Canadian

600 Entomologist 12:1-12. DOI: 10.4039/tce.2017.11.

601 
602 Nervo B, Caprio E, Celi L, Lonati M, Lombardi G, Falsone G, lussig G, Palestrini C, 603 Said-Pullicino D, Rolando A. 2017. Ecological functions provided by dung beetles are 604 interlinked across space and time: evidence from $15 \mathrm{~N}$ isotope tracing. Ecology 98:433605 446. DOI: 10.1002/ecy.1653.

606

607

Pérez-Cogollo LC, Rodríguez-Vivas RI, Delfín-González H, Reyes-Novelo E, Ojeda608

609

610

611

612

613

614

615

616

617

618

619

620

621

622

623

624

625

626

627

628

629

630

631

632

633

634 Chi MM. 2015. Lethal and sublethal effects of overmectin on Onthophagus landolti (Coleoptera: Scarabaeidae). Environmental Entomology 44:1634-1640. DOI: 10.1093/ee/nvv139.

Purtauf T, Dauber J, Wolters V. 2005. The response of carabids to landscape simplification differs between trophic groups. Oecologia 142:458-464. DOI: 10.1007/s00442-004-1740-y.

R Core Team. 2016. R: A language and environment for statistical computing. Vienna, Austria: R Foundation for Statistical Computing.

Sands B, Wall R. 2017. Dung beetles reduce livestock gastrointestinal parasite availability on pasture. Journal of Applied Ecology 54:1180-1189. DOI: 10.1111/13652664.12821.

Sands B, Wall R. 2018. Sustained parasiticide use in cattle farming affects dung beetle functional assemblages. Agriculture, Ecosystems \& Environment 265:226-235. DOI: 10.1016/j.agee.2018.06.012.

Shoop W, Soll M. 2002. Chemistry, pharmacology and safety of the macrocyclic lactones: ivermectin, abamectin and eprinomectin. In: Vercruysse J, Rew RS eds. Macrocyclic Lactones in Antiparasitic Therapy. CABI Publishing Oxon, UK, 1-29.

Skidmore P. 1991. Insects of the British cow-dung community. Shrewsbury, UK: Field Studies Council.

635

Sommer C, Steffansen B, Nielsen BO, Grønvold J, Jensen K-MV, Jespersen JB, Springborg J, Nansen P. 1992. Ivermectin excreted in cattle dung after subcutaneous 636 637 injection or pour-on treatment: concentrations and impact on dung fauna. Bulletin of Entomological Research 82:257-264.

639 Southam CM. 1943. Effects of extract of western red-cedar heartwood on certain wooddecaying fungi in culture. Phytopathology 33:517-524.

640 
641 Tonelli M, Verdú JR, Zunino M. 2018. Effects of the progressive abandonment of

642 grazing on dung beetle biodiversity: body size matters. Biodiversity and Conservation

643 27:189-204. DOI: 10.1007/s10531-017-1428-3.

644

645 Verdú JR, Cortez V, Ortiz AJ, González-Rodríguez E, Martinez-Pinna J, Lumaret J646 P, Lobo JM, Numa C, Sánchez-Piñero F. 2015. Low doses of ivermectin cause 647 sensory and locomotor disorders in dung beetles. Scientific Reports 5:13912. DOI:

648 10.1038/srep13912.

649

650

651

652

653

654

655

656

657

658

659

660

661

662

663

664

665

666

667

668

669

670

Wohde M, Blanckenhorn WU, Floate KD, Lahr J, Lumaret J-P, Römbke J,
Scheffczyk A, Tixier T, Düring R-A. 2016. Analysis and dissipation of the antipt
agent ivermectin in cattle dung under different field conditions. Environmental
Toxicology and Chemistry 35:1924-1933. DOI: 10.1002/etc.3462.

671

Wohde M, Blanckenhorn WU, Floate KD, Lahr J, Lumaret J-P, Römbke J,
Scheffczyk A, Tixier T, Düring R-A. 2016. Analysis and dissipation of the antiparasitic
agent ivermectin in cattle dung under different field conditions. Environmental
Toxicology and Chemistry 35:1924-1933. DOI: $10.1002 /$ etc.3462.

672

Wohde M, Blanckenhorn WU, Floate KD, Lahr J, Lumaret J-P, Römbke J,
Scheffczyk A, Tixier T, Düring R-A. 2016. Analysis and dissipation of the antipt
agent ivermectin in cattle dung under different field conditions. Environmental
Toxicology and Chemistry 35:1924-1933. DOI: 10.1002/etc.3462.

673

674

675

676

Vokřál I, Michaela Š, Radka P, Jiří L, Lukáš $P$, Dominika S, Kateřina L, Barbora S, Lenka S. 2019. Ivermectin environmental impact: excretion profile in sheep and phytotoxic effect in Sinapis alba. Ecotoxicology and Environmental Safety 169:944-949. DOI: 10.1016/j.ecoenv.2018.11.097.

Wickham H. 2016. ggplot2: elegant graphics for data analysis. Springer.

Wickham H, Francois R, Henry L, Müller K. 2015. dplyr: A grammar of data manipulation. $R$ Package Version 0.43.

Williams NM, Crone EE, Roulston TH, Minckley RL, Packer L, Potts SG. 2010. Ecological and life-history traits predict bee species responses to environmental disturbances. Biological Conservation 143:2280-2291. DOI: 10.1016/j.biocon.2010.03.024.

Winfree R, W. Fox J, Williams NM, Reilly JR, Cariveau DP. 2015. Abundance of common species, not species richness, drives delivery of a real-world ecosystem service. Ecology Letters 18:626-635. DOI: 10.1111/ele.12424. 
Figure 1

Demonstrating the large differences in body-size for Onthophagus nuchicornis

Distributions in body-size variation of Onthophagus nuchicornis across male body mass (A), male pronotal width (B), female body mass (C), and female pronotal width (D). Beetles from the smaller end of the body-size spectrum are filled in light grey. Beetles from the larger end of the body-size spectrum are filled in dark grey. In all cases differences in means were statistically significant with large effect sizes (minimum 15\% difference).
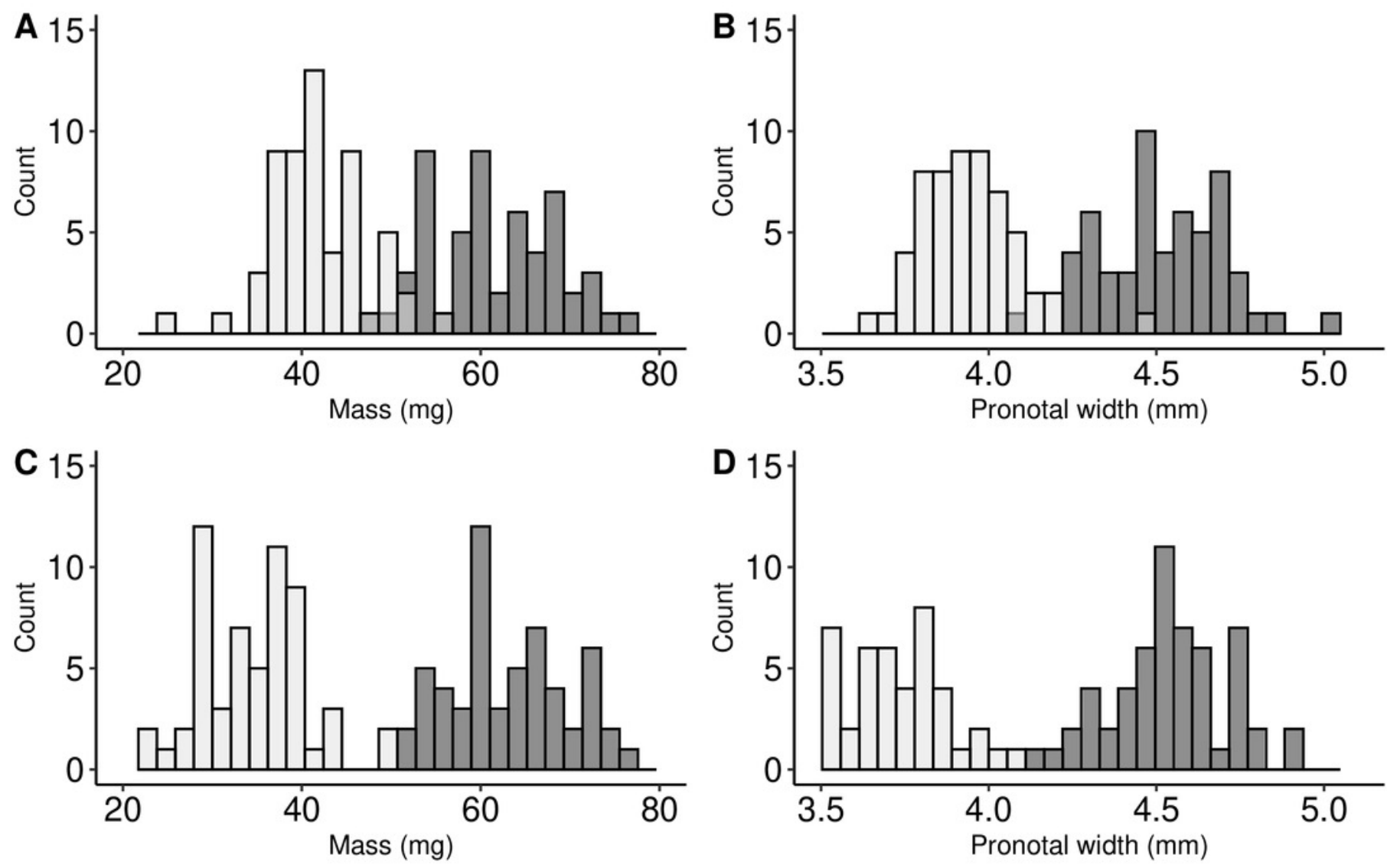


\section{Figure 2}

Larger dung beetles are more functionally efficient than smaller dung beetles.

Comparison of three different measures of functional efficiency in response to body size in the dung beetle Onthophagus nuchicornis. Body size is an important predictor of functional efficiency. Larger beetles bury more dung than small beetles (A), which is facilitated by larger beetles burying a larger number of brood balls than smaller beetles (B) in greater abundances (C). The lower and upper limits of the box represent the inter quartile range (IQR) of the data. The horizontal line within each box represents the median. Whiskers extend from the boxes to show maximum and minimum values; if this distance is $>1.5 \times$ the IQR, observations appear as a filled point.
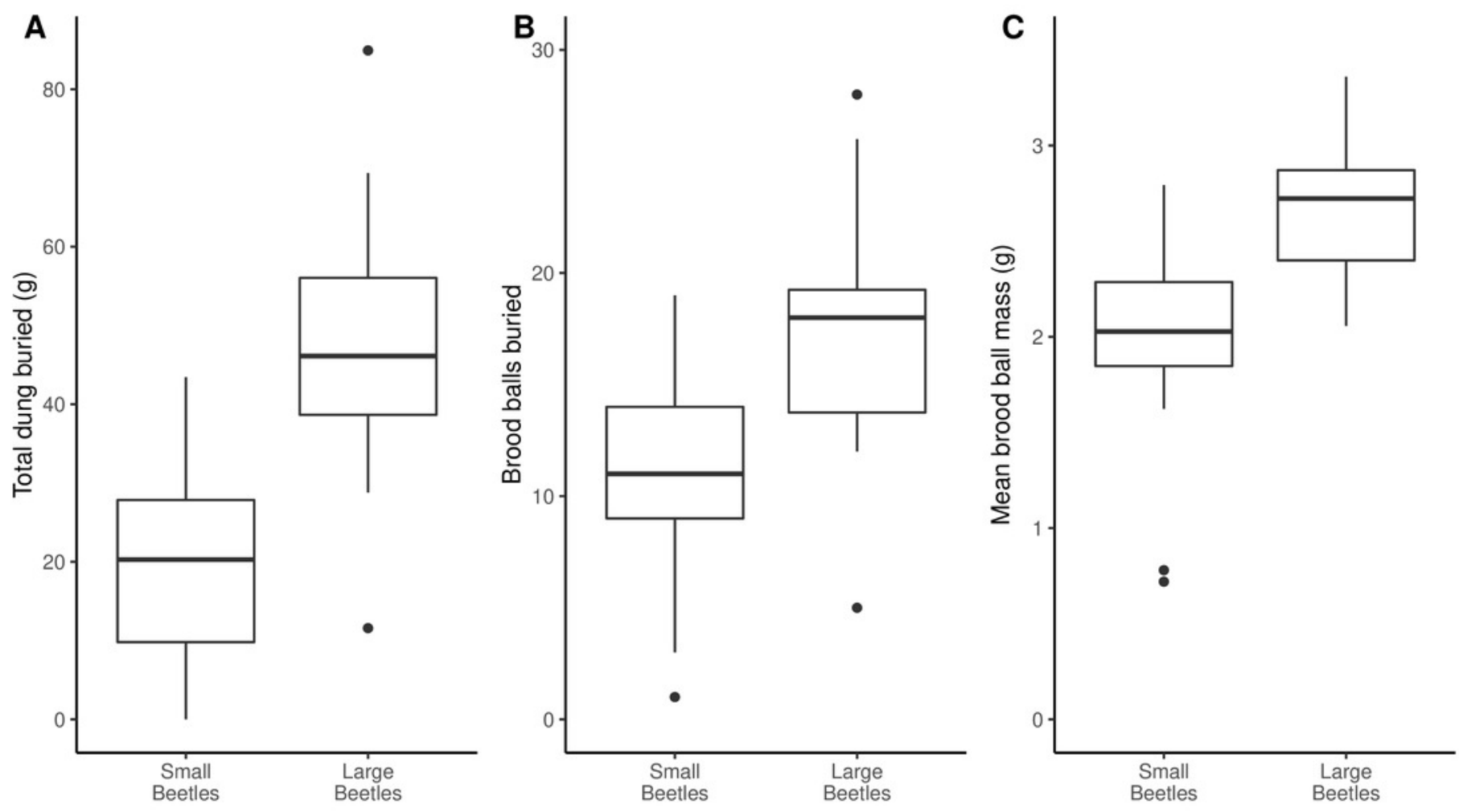
Figure 3

High doses of ivermectin cause mortality in the dung beetle Onthophagus nuchicornis Mortality of Onthophagus nuchicornis exposed to ivermectin in dung. Mortality varied with ivermectin concentration, but body size did not affect susceptibility to ivermectin by itself, or via any exposure-body size interaction. Points are mean values with associated standard errors.

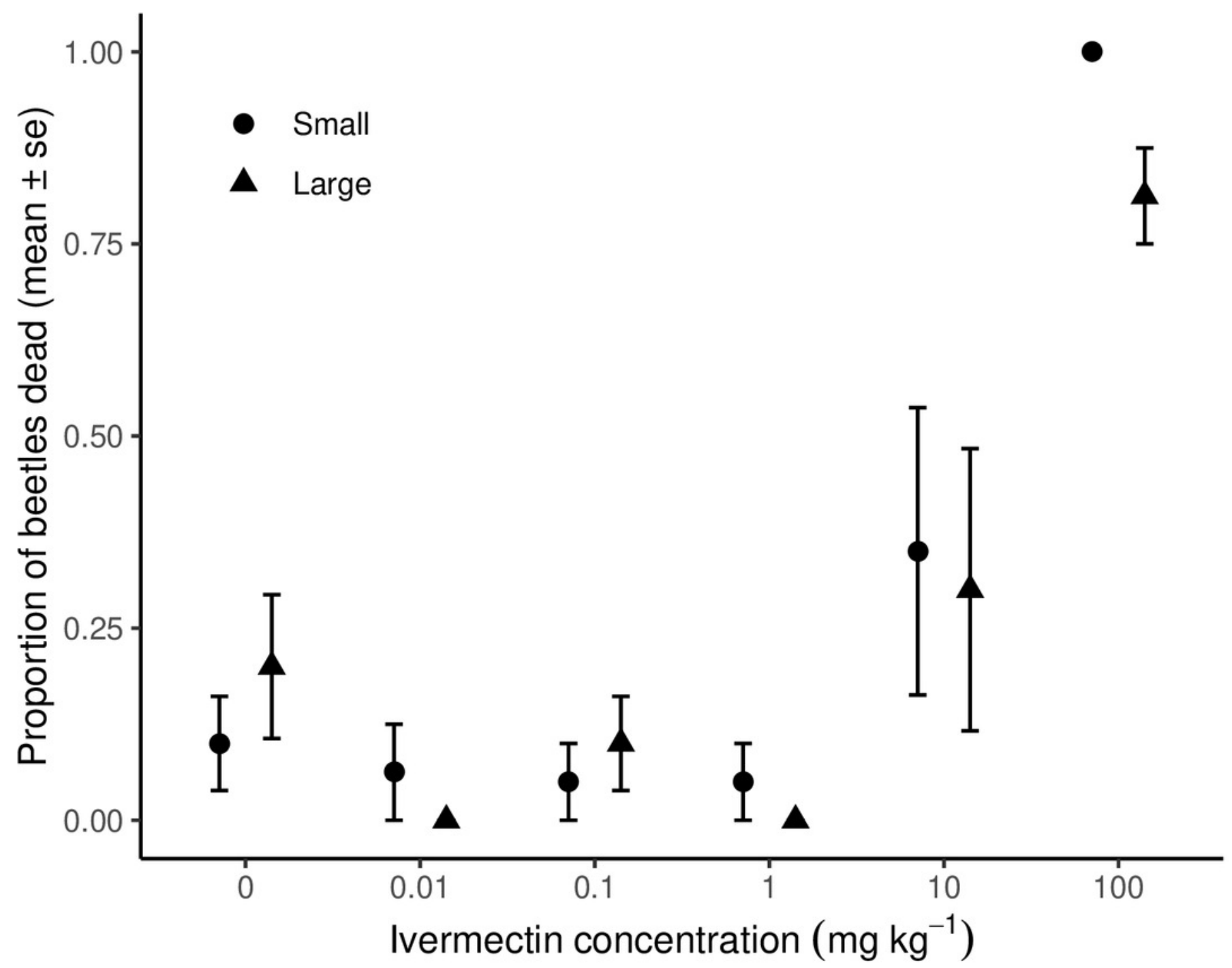




\section{Figure 4}

Exposure to low doses of ivermectin stimulate functioning in the dung beetle Onthophagus nuchicornis

Low exposure to ivermectin enhances the ecosystem function of dung burial. Larger beetles continue to be more functionally efficient than smaller beetles, regardless of ivermectin exposure. In each case, the higher level of functioning observed (A) was driven by greater brood ball production (B), rather than the production of heavier brood balls (C). Points represent means and associated standard errors.
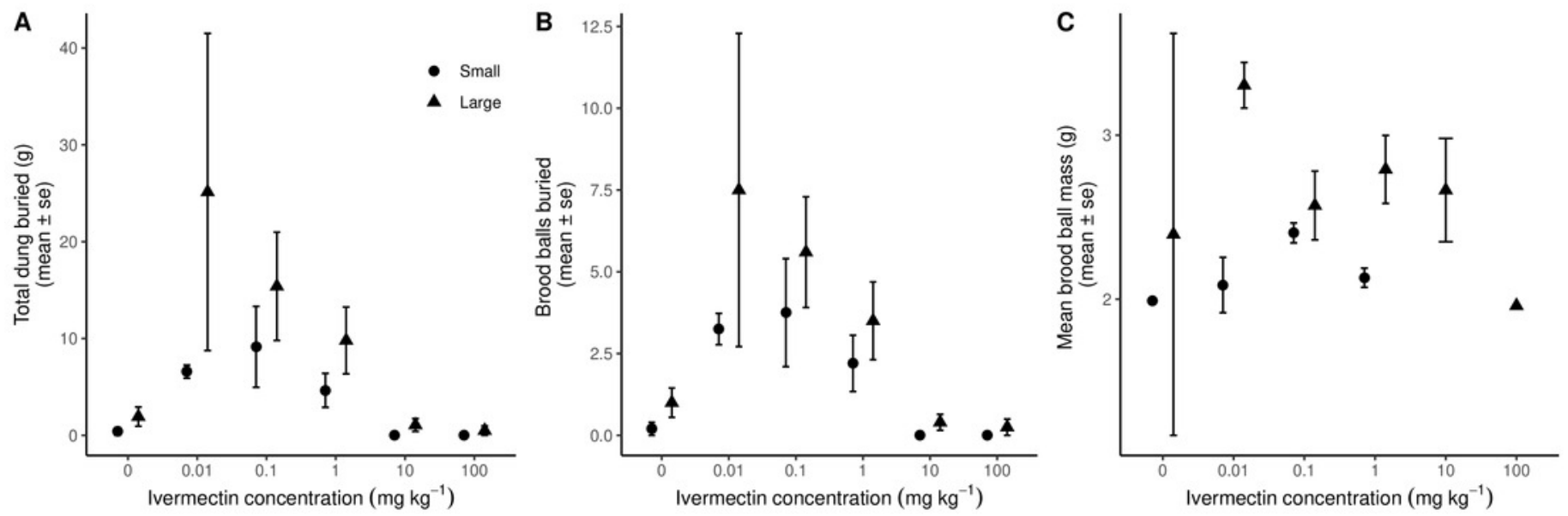